\title{
Cirugía y cirujanos, su devenir histórico
}

\author{
Surgery and surgeons, their historical evolution
}

\author{
G. Manuel Marrón-Peña* \\ Academia Mexicana de Cirugía, Colegio Mexicano de Anestesiología, Ciudad de México, México
}

Se menciona que en los eventos científicos organizados por médicos cirujanos en el primer tercio del siglo $\mathrm{xx}$ se incluyeron en sus programas académicos algunos temas relacionados con la anestesiología. Entre los cursos importantes en los que se participó están el organizado en el año 1930 por la Asociación Médica Mexicana en el Hospital Juárez, y el que realizó en 1932 la Sociedad Médica del Hospital General de la Ciudad de México',2.

El año 1933 es un icono en la historia de la medicina nacional. En esa época se implementa un proyecto político que impulsaba la educación y la salud para toda la población, y también hubo otros tres acontecimientos importantes que ayudaron a enmarcar el nacimiento de la Academia Mexicana de Cirugía (AMC) y del Colegio Mexicano de Anestesiología (1934), antes Sociedad Mexicana de Anestesiología:

- La AMC es fundada el 13 de enero de 1933, firmando su acta constitutiva 60 eminentes cirujanos, entre los que destacan su primer presidente, el Acad. Dr. Gonzalo Castañeda Escobar, y tres médicos con una gran visión, cirujanos de formación, pero además muy preocupados por aliviar el dolor que produce el acto quirúrgico, es decir, por la anestesia, a la que se dedicarían en cuerpo y alma la mayor parte de su vida; estos inquietos hombres fueron el Acad. Dr. Don Benjamín Bandera Cardeña, el Acad. Dr. Don Emilio Varela y el Acad. Dr. Don Juan White Morquecho. Ellos son los artífices de la anestesiología mexicana, son sus raíces y los cimientos sobre los que descansa ${ }^{1,2}$. El acta de protocolización de la
AMC se redacta el 2 de febrero, y la ceremonia solemne de su fundación fue el día 2 de junio de 1933, considerándose esta como la fecha oficial de su constitución'.

- La comunidad médica mexicana realizaba en 1933 los preparativos para la celebración del centenario de la fundación del Es'cimiento de las Ciencias Medicas, y para ello la Academia Nacional de Medicina y la Facultad de Medicina de la Universidad Nacional Autónoma de México (UNAM) actuaban colaborando en la organización del magno evento, que contemplaba un homenaje a Don Valentín Gómez Farías, su fundador, y a los primeros profesores del plantel, así como una serie de conferencias históricas acerca de dicho establecimiento y distintos cursos entre los que destacó el de cirugía que dictó el Dr. Ulises Valdés, en el cual se destinó una lección a la anestesiología ${ }^{2}$.

- El 1 de febrero de 1933, el Dr. Ignacio Chávez Sánchez tomo posesión como director de la Facultad de Medicina de la UNAM en el antiguo Palacio de Medicina, que otrora fuera el recinto de la Santa Inquisición. El nuevo directivo se sumó inmediatamente a la organización de los festejos del centenario, lo mismo que la AMC; los homenajes culminaron el día 23 de octubre de 1933, dando origen a una medicina quirúrgica mexicana más cientifica ${ }^{1,2}$.

Los citados antecedentes, entre otros, enmarcan la creciente inquietud existente en los médicos cirujanos, particularmente en los que ejercían la anestesiología, que deseaban agruparse para compartir sus 
Cirugía y Cirujanos. 2018;86

Tabla 1. Algunos directores editoriales de la revista Cirugía y Cirujanos ${ }^{1}$

\begin{tabular}{lll}
\hline Nombre & Cargo & Periodo \\
\hline Acad. Dr. José Aguilar Alvares & Primer director & Agosto 1933 a diciembre 1936 (inicio) \\
Acad. Dr. Manuel Mateos Fournier & Director gerente & Febrero 1942 a enero 1944 (décimo aniversario 1943) \\
Acad. Dr. Guillermo Alamilla Gutiérrez & Director & Febrero 1956 a febrero 1958 (vigésimo quinto aniversario 1958) \\
Acad. Dr. Nicolás Figueras Carrera & Director y editor & Enero 1982 a diciembre 1984 (quincuagésimo aniversario 1983) \\
Acad. Dr. Alejandro Reyes Fuentes & Director & (septuagésimo quinto aniversario 2008) \\
Acad. Dr. Raúl Carrillo Esper & Editor & Enero 2018 a la fecha \\
\hline
\end{tabular}

experiencias, comunicar las investigaciones que hacían, y dar a conocer sus motivaciones culturales, académicas y gremiales. Deseaban organizar cursos y publicar sucesos acerca de las disciplinas que ejercían.

Ese 1933 de efervescencia cultural, educativa y científica es un motor para que todos quieran actuar, colaborar, participar y ser creativos. Se hacen planes y proyectos, de los que algunos fracasarán, pero otros serán el preámbulo de futuros y grandes acontecimientos, como fue la creación de la revista Cirugía y Cirujanos en 1933. Tan solo un poco después de fundada la AMC se publica en el mes de agosto el primer número de esta revista, convirtiéndose en su órgano oficial, que conserva al día de hoy su nombre original y aparece bimensualmente en forma ininterrumpida hasta la fecha, lo que el presente artículo editorial tiene como propósito y motivo principal ${ }^{1,3}$. El trabajo realizado por sus directivos ha sido arduo, tenaz y continuo. Las vicisitudes eran y son siempre muchas, primordialmente las económicas, por lo que deseo rendir un gran homenaje a todos los que han colaborado en su publicación, sin olvidar al primer tesorero, el Acad. Dr. Francisco J. Campos L., quien en algunas ocasiones donaba una valiosa joya para sufragar los costos de la publicación, que inicialmente era mensual y se pagaba por la propia AMC y por la Secretaria de Salubridad ${ }^{1,3}$. Es la falta de espacio lo que solo me permite mencionar a aquellos directores o editores que han estado presentes en los años de inicio, en los años décimo, vigésimo quinto, quincuagésimo y septuagésimo quinto, y en el momento actual aludir a quien la dirige, porque son estos los años mas representativos históricamente de la vida académica de nuestra publicación. En la tabla 1 se mencionan dichos directivos, por lo que ofrezco una disculpa a todos aquellos que fueron omitidos, como ya se dijo, por falta de sitio, pero que están completos en el libro Historia de la Academia, de Hurtado Andrade'.

Llama la atención que entre los 60 fundadores de la AMC y de Cirugía y Cirujanos existan médicos ciruja- se consagraran por mas tiempo a ella, al grado que el 20 de noviembre de 1934, junto con otros colegas, siguieran el ejemplo y constituyeran la Sociedad de Anestesistas de México ${ }^{2,4,5}$, que a partir de 1948 se llamó Sociedad Mexicana de Anestesiología, y que desde 1994 lleva por nombre Colegio Mexicano de Anestesiología $2,4,5$. El académico Dr. Raúl Carrillo Esper fue su presidente en el bienio 2006-2007, lo mismo que de la Sociedad de Medicina Crítica y Terapia Intensiva; es miembro de la Academia Nacional de Medicina y titular de la AMC, a la que ingresó en el año 2000 demostrando su gran bonhomía y su interés por la investigación y la docencia, haciéndole merecedor de ser el titular de la Comisión de Enseñanza de nuestra corporación. Desde 2008 es el director editorial de la Revista Mexicana de Anestesiología y de las Clínicas Mexicanas de esta especialidad, así como autor de varios textos de la misma, lo cual asegura una gran experiencia en publicaciones médicas, garantizando así que Cirugía y Cirujanos desde este 2018 esté segura, en muy buenas manos, y que seguirá adelante en su inmejorable trayectoria, ciertamente incrementando día a día su gran trascendencia dentro de la cirugía mexicana, porque el Dr. Carrillo Esper, como su nuevo editor, logrará cumplir con los objetivos planteados y con aquellos que sean elaborados por los socios y los directivos. Enhorabuena a nuestra revista y a nuestra institución. Que el éxito corone su gestión para bien de los académicos, de la cirugía y de la medicina mexicanas.

\section{Bibliografía}

1. Hurtado AH. Revista Cirugía y Cirujanos. En Hurtado AH, editor. Historia de la Academia Mexicana de Cirugía. 1933-2002. México: Copias Gráficas S.A de C.V.; 2005. p. 231-50.

2. Marrón PM. Antecedentes históricos del Colegio Mexicano de Anestesiología, antes Sociedad Mexicana de Anestesiología. Sus orígenes, evolución y trascendencia. 1934-1995. Rev Mex Anest. 2013;36:136-54.

3. Hurtado AH, Sigler MI, De la Torre Bravo A. Breve reseña histórica de Cirugía y Cirujanos. Cir Ciruj.1998;66:207-11.

4. Bandera B. Historia de la anestesiología en México: evolución y desarrollo futuro. Rev Mex Anest. 1960;(9):83-94.

5. Aldrete JA. Historia de la anestesiología. Texto de anestesiología teórico-práctica. México: Salvat Mexicana de Ediciones; 1986. p. 3-23. 